Pesq. Vet. Bras. 38(2):335-339, fevereiro 2018

\title{
Osteossíntese de rádio e ulna em Gavião Caboclo (Buteogallus meridionalis) $^{1}$
}

\author{
Ísis S. Dal-Bó ${ }^{*}$, Vanessa C.M. Ferraz ${ }^{3}$, Olicies da Cunha ${ }^{4}$ e Cássio R.A. Ferigno²
}

\begin{abstract}
Dal-Bó I.S., Ferraz V.C.M., Cunha O. \& Ferrigno C.R.A. 2018. [Radius and ulna osteosynthesis in a Savanna Hawk (Buteogallus meridionalis).] Osteossíntese de rádio e ulna em Gavião Caboclo (Buteogallus meridionalis). Pesquisa Veterinária Brasileira 38(2):335-339. Departamento de Cirurgia, Universidade de São Paulo, Av. Prof. Dr. Orlando Marques de Paiva 87, Cidade Universitária, São Paulo, SP 05508-270, Brazil. E-mail: idb_vet@yahoo.com.br

A wild Savanna Hawk (Buteogallus meridionalis) of unknown history, was seen at the veterinary hospital. The patient presented with a dropped right wing and soft tissue damage that appeared to be a recent wound involving the right radius and ulna region, characterizing an open fracture grade II. The radiological findings were a comminuted complete fracture of the ulnar diaphysis and complete transverse fracture of the radial diaphysis. Stabilization of the radius fracture was performed with a $1.5 \mathrm{~mm}$ miniplate with 6 holes, with 2 proximal screws and 2 distal screws, and ulna osteosynthesis with a $2.0 \mathrm{~mm}$ locking plate with 12 holes, with 3 proximal screws and 2 distal screws. At 180 postoperative days, the implants were removed and the patient was discharged. The use of locking plate for the treatment of open fractures in ulna of Savanna Hawks may provide adequate healing and return to limb function being able to fly.

INDEX TERMS: Radius, ulna, osteosynthesis, Savanna Hawk, Buteogallus meridionalis, fracture, bird, bone, plate, wild birds, surgery.
\end{abstract}

RESUMO.- Foi atendido um Gavião Caboclo (Buteogallus meridionalis), de vida livre e histórico desconhecido. 0 paciente apresentava impotência funcional da asa direita e solução de continuidade de aspecto recente envolvendo a região de rádio e ulna direitos caracterizando fratura aberta grau II. Os achados radiológicos foram fratura completa cominutiva de diáfise média de ulna e fratura completa tranversa de diáfise média de rádio. A estabilização da fratura de rádio foi realizada com miniplaca de $1,5 \mathrm{~mm}$ de 6 orifícios, com 2 parafusos proximais e 2 parafusos distais e, osteossíntese de ulna com placa bloqueada de $2,0 \mathrm{~mm}$ de 12 orifícios, com 3 parafusos proximais e 2 parafusos distais. Aos 180 dias de pós-operatório, os implantes ortopédicos foram removidos e o paciente recebeu alta. Conclui-se que o emprego de placa

\footnotetext{
${ }^{1}$ Recebido em 14 de maio de 2017.

Aceito para publicação em 21 de julho de 2017.

${ }^{2}$ Departamento de Cirurgia, Faculdade de Medicina Veterinária e Zootecnia, Universidade de São Paulo (USP), Av. Prof. Dr. Orlando Marques de Paiva 87, Cidade Universitária, São Paulo, SP 05508-270, Brasil. *Autor para correspondência: idb_vet@yahoo.com.br.

${ }^{3}$ Médica Veterinária autônoma, São Paulo, SP.

${ }^{4}$ Departamento de Ciências Veterinárias, Faculdade de Medicina Veterinária, Universidade Federal do Paraná (UFPR), Campus Palotina, Rua Pioneiro 2153, Palotina, PR 85950-000, Brasil.
}

bloqueada para tratamento de fraturas abertas em ulna de Gavião Caboclo, pode propiciar adequada consolidação e retorno à função do membro sendo capaz de voar.

TERMOS DE INDEXAC̄̃̃o: Osteossíntese, rádio, ulna, Gavião Caboclo, Buteogallus meridionalis, fratura, ave, osso, placa, aves silvestres, cirurgia.

\section{INTRODUÇÃO}

Os ossos longos das aves apresentam canal medular de diâmetro proporcionalmente maior, corticais ósseas finas e quebradiças em virtude da alta densidade de cálcio presente, além de trabéculas ósseas finas e distribuídas ao longo de todo o osso, com menor quantidade de osso denso na região metafisária quando comparados aos dos mamíferos (Ferraz et al. 2008, Dal-Bó et al. 2012).

0 rádio e a ulna, nas aves, formam paralelograma por meio das suas articulações com o úmero, com os ossos do carpo e entre si. A manutenção do deslizamento longitudinal entre esses dois ossos é tão importante quanto o movimento articular de flexão e extensão (Beaufrère et al. 2012). As fraturas envolvendo apenas um dos ossos apresentam melhor prognóstico desde que não envolvam a superfície 
articular e não haja formação de sinostose entre o rádio e ulna, pois isto limita a extensão da asa e a sua função durante o vôo (MacCoy 1992).

Os traumas envolvendo a região diafisária média apresentam prognóstico reservado devido à potencial formação de sinostose e aos danos ao suprimento vascular da extremidade do membro. Os segmentos ósseos, em geral, são grandes e vários métodos de osteossíntese como pinos intramedulares, fixadores esqueléticos externos e placas e parafusos podem ser aplicados dependendo do tamanho e do temperamento do paciente (MacCoy 1992).

As placas promovem estabilidade rígida e manutenção da redução anatômica, permitindo retorno precoce à função do membro. Esses implantes contrapõem as forças de rotação, arqueamento, compressão e cisalhamento. Em aves, a vantagem das placas, é a excelente tolerância dos pacientes ao implante, uma vez que o mesmo é interno e confere formação de calo ósseo mínimo (Davidson et al. 2005 Guzman et al. 2007).

0 presente trabalho tem por objetivo descrever a osteossíntese de fratura aberta de rádio e ulna utilizando placa bloqueada e miniplaca em um Gavião Caboclo (Buteogallus meridionalis).

\section{RELATO DA CIRURGIA}

Foi atendido no Laboratório de Ortopedia e Traumatologia Comparada do Departamento de Cirurgia da Faculdade de Medicina Veterinária e Zootecnia da Universidade de São Paulo (LOTC-FMVZ/USP), um Gavião Caboclo (Buteogallus meridionalis), adulto, de sexo indefinido, de 940 gramas de massa corporal apresentando impotência funcional da asa direita. O histórico recente do paciente era desconhecido, uma vez que se tratava de animal de vida livre.

Ao exame físico, foi observada solução de continuidade de aspecto recente envolvendo a região diafisária média de rádio e ulna direitos (faces lateral e medial) caracterizando fratura aberta grau II. Os demais parâmetros fisiológicos encontravam-se dentro dos valores normais para a espécie. Foi realizado estudo radiológico nas projeções mediolateral (ML) e craniocaudal ( $\mathrm{CrCa}$ ), os quais evidenciaram fratura aberta completa cominutiva de diáfise média de ulna e fratura aberta completa tranversa de diáfise média de rádio, ambas com desvio do eixo ósseo (Fig.1A,B).

0 paciente foi submetido à cirurgia para estabilização das fraturas. Como medicação pré-anestésica, foram utilizados butorfanol (1mg.kg-1), cetamina (20 mg. $\left.\mathrm{kg}^{-1}\right)$ e midazolam (1 mg. $\mathrm{kg}^{-1}$ ) por via intramuscular (IM). A indução anestésica foi realizada através da vaporização de sevoflurano em oxigênio a 100\% em máscara. Foi procedida intubação endotraqueal e a manutenção anestésica foi realizada com sevoflurano vaporizado em oxigênio a $100 \%$ em sistema aberto. A ave foi posicionada em decúbito dorsal, realizou-se remoção manual das penas e antissepsia com solução de clorexidine a $0,2 \%$.

Após a colocação dos panos de campo, foi feita abordagem cirúrgica à diáfise de rádio e ulna a partir da lesão cutânea pré-existente na face medial. Foi realizada irrigação copiosa da ferida com solução de $\mathrm{NaCl}$ a 0,9\% sob pressão e exposição adequada dos segmentos ósseos para redução da fratura e osteossíntese de rádio com miniplaca de 1,5 mm de 6 orifícios, com 2 parafusos proximais e 2 parafusos distais e, osteossíntese

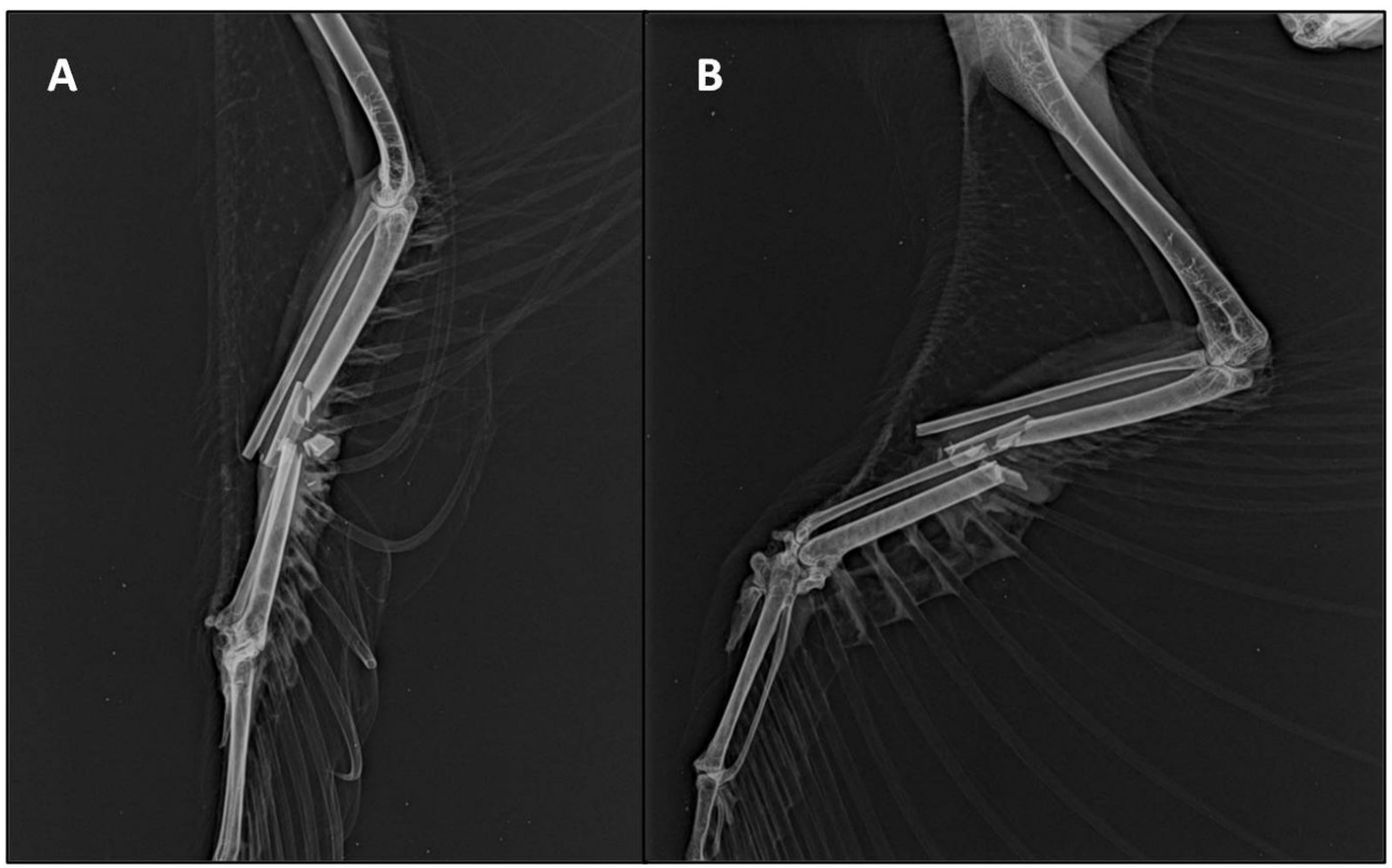

Fig.1. Imagens radiográficas de rádio e ulna direitos do Gavião Caboclo (Buteogallus meridionalis). (A e B) Imagens pré-operatórias, nas projeções CrCa e ML respectivamente, evidenciando fraturas abertas completas diafisásias médias cominutiva de ulna e transversa de rádio, com desvio do eixo ósseo. 


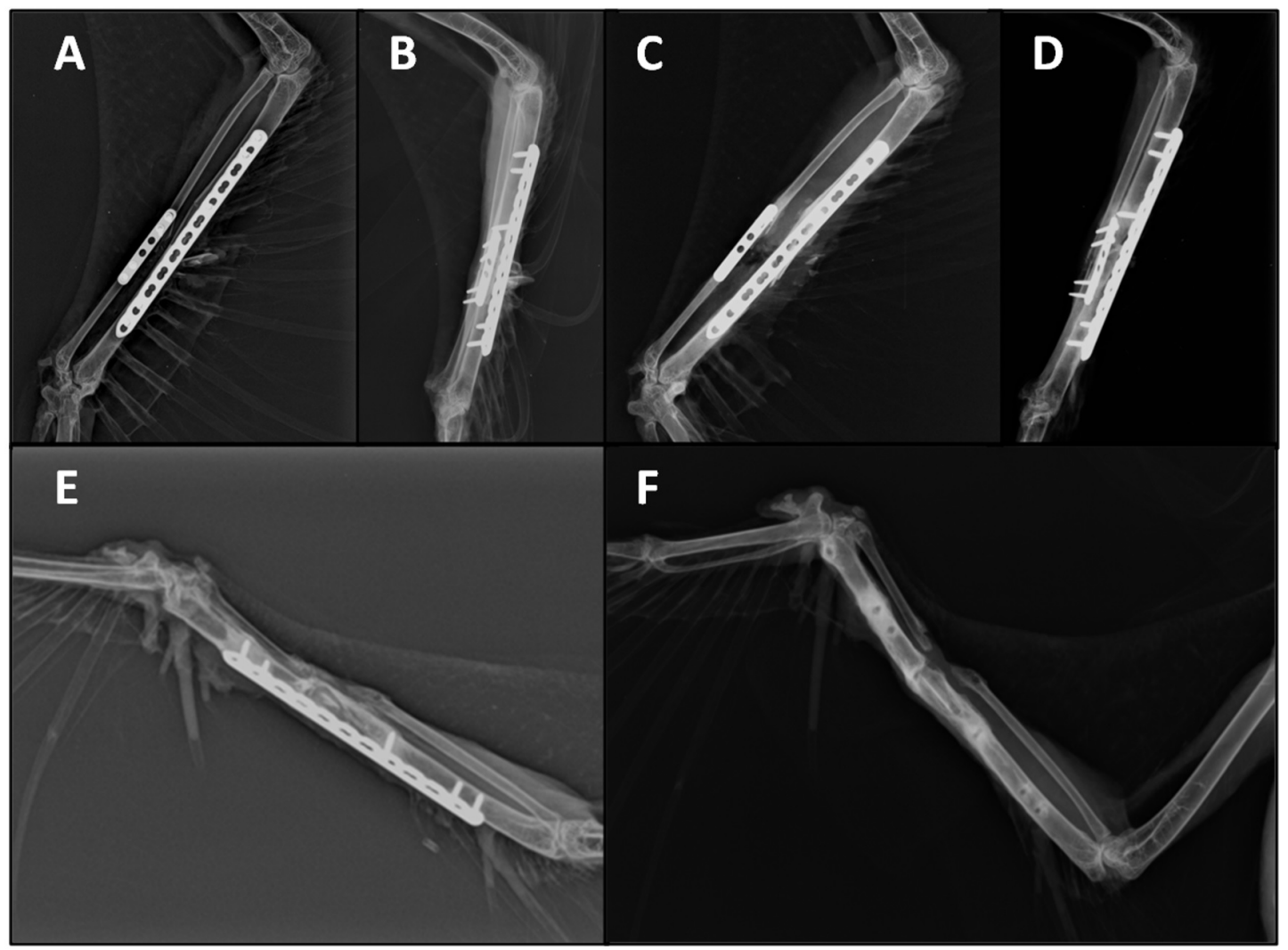

Fig.2. Imagens radiográficas de rádio e ulna direitos do Gavião Caboclo (Buteogallus meridionalis). (A e B) Imagens do PO imediato, nas projeções ML e CrCa, onde observam-se ambas as fraturas alinhadas e manutenção do comprimento ósseo. (C e D) Imagens aos 30 dias de PO, nas mesmas projeções evidenciando consolidação da fratura ulnar e ausência de sinostose. (E e F) Imagens referentes aos 180 dias de PO, na projeção ML, antes de depois da remoção dos implantes, respectivamente.

de ulna com placa bloqueada (Locking compression plate - LCP) de 2,0 mm de 12 orifícios, com 3 parafusos proximais e 2 parafusos distais (todos bloqueados) exercendo a função de apoio. A ferida cirúrgica e a localizada na face lateral da asa foram desbridadas e, em seguida, novamente irrigadas com solução de $\mathrm{NaCl}$ a $0,9 \%$ sob pressão. A síntese das fáscias musculares e tecido subcutâneo foi procedida com fio poliglecaprone 4-0 em padrão simples contínuo. A oclusão da ferida foi obtida por meio de sutura captonada com fio poliamida 3-0 em padrão Wolff. 0 mesmo foi realizado para tratamento da ferida da face lateral da asa. 0 paciente foi mantido com bandagem "em oito" até a remoção dos pontos de pele aos quinze dias de evolução. Foram administrados enrofloxacina $15 \mathrm{mg}_{\mathrm{kg}}{ }^{-1}$, IM, a cada 12 horas, durante 10 dias como terapia antimicrobiana e, butorfanol $1 \mathrm{mg} . \mathrm{kg}^{-1}$, IM, a cada 12 horas, por 5 dias associado a meloxicam $0,3 \mathrm{mg} \mathrm{kg}^{-1}$, IM, a cada 12 horas, durante 5 dias para analgesia.

Foi realizado estudo radiológico no pós-operatório (PO) imediato, nas projeções ML e CrCa, onde foram observadas fraturas alinhadas e manutenção do comprimento ósseo (Fig.2A,B) em comparação às radiografias do membro contralateral realizadas para planejamento cirúrgico. Aos 30 dias de P0, nas mesmas projeções, foi demonstrada completa consolidação óssea da ulna (Fig.2C,D) e ausência de sinais radiológicos de osteomielite. No mesmo período, o paciente também não demonstrou sinais clínicos de infecção óssea Aos 180 dias de PO, observou-se remodelamento do calo ósseo e ausência de reabsorção óssea ao redor dos implantes. Não houve união radiográfica do rádio (Fig.2E,F).

Nesse momento, optou-se pela retirada dos implantes uma vez que havia possibilidade de reintrodução da ave ao meio ambiente. Para tanto foram utilizados o mesmo protocolo anestésico, mesma abordagem cirúrgica bem como o mesmo manejo PO. Após 15 dias da remoção dos implantes, foram retirados os pontos de sutura e o paciente recebeu alta. 0 animal não apresentava restrição da amplitude de movimento das articulações úmero-rádio-ulnar e carpo-rádio-ulnar, sendo capaz de voar. A ave foi mantida em cativeiro por 4 meses para acompanhamento da evolução.

\section{DISCUSSÃO}

As aves possuem ossos de baixo peso e de alta resistência aerodinâmica apesar de suas finas corticais. As fraturas nesses animais são frequentemente abertas e cominutivas devido à mínima cobertura por tecidos moles (Doneley 2010, Gull et al. 2012), como foi observado no paciente do presente relato.

As fraturas envolvendo unicamente o rádio, em geral, não requerem reparo cirúrgico a menos que apresentem deslocamento ou instabilidade. A ulna é o principal suporte ósseo dessa região e as fraturas envolvendo somente esse osso geram estresse no rádio favorecendo o surgimento de fraturas. A estabilização cirúrgica da ulna é, portanto, indicada 
para o retorno à função (MacCoy, 1992, Beaufrère et al. 2012). Optou-se pela osteossíntese dos dois ossos para evitar a formação de sinostose, pois havia a possibilidade de reintrodução do paciente ao meio ambiente. No entanto, a consolidação óssea foi observada apenas na ulna, possivelmente devido a menor perda óssea nessa região, não ocorrendo desenvolvimento de sinostose.

Alguns princípios da cirurgia ortopédica em aves são: minimizar danos aos tecidos moles, promover estabilização rígida, manutenção do alinhamento, do comprimento e orientação rotacional e angular e, sobretudo, retorno precoce à função (Doneley 2010). Os mesmos foram respeitados durante a realização das osteossínteses no paciente desse relato e a manutenção do comprimento ósseo se deve à realização de imagens do membro contralateral para planejamento cirúrgico e utilização de placa para osteossíntese tanto do rádio como da ulna, o que evitou a formação de sinostose e, consequentemente, favoreceu a utilização precoce da asa.

Diversos métodos de estabilização de fraturas são descritos em aves, como coaptação externa, pinos intramedulares metálicos ou não, fixadores esqueléticos externos e placas e parafusos além de associações dos mesmos (Teixeira et al. 2004). As placas não são amplamente utilizadas nesses animais devido à escassez de sistemas "miniatura" e em virtude da fragilidade de suas corticais ósseas, as quais não promovem "pega" adequada dos parafusos (Christen et al. 2005). Nesse caso, apesar de se tratar de uma ave de porte médio, foi possível a osteossíntese do rádio e da ulna com aplicação de miniplaca de $1,5 \mathrm{~mm}$ e placa bloqueada de $2,0 \mathrm{~mm}$, respectivamente, não sendo relatada fragilidade das corticais, dificuldades durante a intervenção cirúrgica ou falha dos implantes.

Há relatos da utilização de placa para osteossíntese da ulna e pino intramedular para estabilização do rádio (Christen et al. 2005). Não foi utilizada tal associação em virtude das desvantagens do uso dos pinos intramedulares, como possibilidade de trauma articular e aos tecidos periarticulares durante sua inserção, lesão vascular do canal intramedular e perpetuação da contaminação óssea, uma vez que se tratava de fratura aberta (Teixeira et al. 2004, Christen et al. 2005). Além disso, os ossos das aves estão mais expostos às forças de torção em comparação aos dos mamíferos, que são principalmente expostos à compressão e ao arqueamento (Gull et al. 2012). Pinos intramedulares, não neutralizam as forças de rotação (Christen et al. 2005) sendo, portanto, contraindicados para tratamento de fraturas transversas como a do paciente do presente relato.

Nas placas bloqueadas, o encaixe da cabeça rosqueada do parafuso ao orifício igualmente rosqueado da placa impede a movimentação entre as partes individuais do implante. Em caso de falha do implante, todos os parafusos de um segmento devem se soltar para a estabilidade ser perdida (Ferrigno et al. 2011). Outra vantagem conferida por esse método de fixação é sua atuação como apoio não necessitando reconstrução anatômica da coluna óssea. Além disso, não há necessidade de retorcimento perfeito uma vez que a resistência do sistema não se dá pelo atrito da placa com o periósteo e sim pelo contato da placa com a cabeça do parafuso causando, portanto, menores danos ao suporte vascular periosteal (Rutherford \&Ness, 2012). Todas essas características dos sistemas bloqueados foram consideradas na escolha do implante a ser utilizado para osteossíntese de ulna, uma vez que se tratava de fratura cominutiva e aberta, que pôde ser estabilizada com apenas 3 parafusos proximais e 2 distais. 0 reduzido número de parafusos foi suficiente para estabilização da fratura e também para evitar fragilização óssea e fratura iatrogênica.

A desvantagem do uso de placas em aves, contudo, é a necessidade de remoção em pacientes que serão reintroduzidos, o que implica em anestesia geral e ampla abordagem cirúrgica (Davidson et al. 2005). Nesse caso, optou-se pela remoção dos implantes não apenas pela possibilidade de reintrodução do paciente ao meio ambiente, mas também como medida preventiva, já que se tratava de fratura aberta e havia possibilidade de osteomielite futuramente. Ambas as placas foram removidas, mesmo não havendo consolidação na fratura radial já que a ulna desempenha o principal suporte ósseo nessa região.

\section{CONCLUSÃO}

Conclui-se que o emprego de placa bloqueada 2,0 $\mathrm{mm}$ para osteossíntese de ulna em fratura aberta de um Gavião Caboclo (Buteogallus meridionalis), pode propiciar adequada consolidação e retorno à função do membro.

\section{REFERÊNCIAS}

Beaufrère H., Ammersbach M., Nevarez J., Heggem B. \& Tully T.N. Jr 2012. Successful treatment of a radioulnar synostosis in a Mississippi Kite (Ictinia mississippiensis). J. Avian Med. Surg. 26(2):94-100. PMid:22872982. http:// dx.doi.org/10.1647/2011-008.1

Christen C., Fischer I., Von Rechenberg B., Flückiger M. \& Hatt J.M. 2005. Evaluation of a maxillofacial miniplate compact 1.0 for stabilization of the ulna in experimentally induced ulnar and radial fractures in pigeons (Columba livia). J. Avian Med. Surg. 19(13):185-190. http://dx.doi. org/10.1647/2004-010.1.

Dal-Bó Í.S., Chagas J.A.B., Oliveira R.P., Ferreira M.P., Nóbrega F.S., Quadros A.M., Spasin J.E. \& Brun M.V. 2012. Osteossíntese de tibiotarso com fixador esquelético externo transarticular tipo II em gavião carrapateiro (Milvago chimachima): relato de caso. Medvep - Revta Cient. Med. Vet. Pequenos Animais Animais Estimacao 10(32):56-60.

Davidson J.R., Mitchell M.A. \& Ramirez S. 2005. Plate fixation of a coracoid fracture in a bald eagle (Haliaeetus leucocephalus). J. Avian Med. Surg. 19(4):303-308. http://dx.doi.org/10.1647/2004-037.1.

Doneley B. 2010. Avian Medicine and Surgery in Practice Companion and Aviary birds. Manson Publishing, London. 336p.

Ferraz V.C.M., Ferrigno C.R.A., Cortopassi S.R.G., Lopes R.S., Isaza R. \& Kim S. 2008. Avaliação radiográfica e de função de vôo após fixação após fixação de osteotomias distais do úmero em pombas (Columba livia), com modelo de fixador externo articulado. Pesq. Vet. Bras. 28(8):351-357. http://dx.doi. org/10.1590/S0100-736X2008000800001.

Ferrigno C.R.A., Cunha O.D., Caquias D.F.I., Ito K.C., Nina M.I.D., Mariani T.C. \& Ferraz V.C.M. 2011. Resultados clínicos e radiográficos de placas ósseas bloqueadas em 13 casos. Braz. J. Vet. Res. Anim. Sci. 48(6):512-518. http:// dx.doi.org/10.11606/S1413-95962011000600010.

Gull J.M., Saveraid T.C., Szabo D. \& Hatt J.M. 2012. Evaluation of three miniplate systems for fracture stabilization in pigeons (Columba livia). J. Avian Med. Surg. 26(4):203-212. PMid:23409431. http://dx.doi.org/10.1647/2010062R1.1. 
Guzman D.S.M., Bubenik L.J., Lauer S.K., Vasanjee S. \& Mitchell M.A. 2007. Repair of a coracoid luxation and a tibiotarsal fracture in a bald eagle (Haliaeetus leucocephalus). J. Avian Med. Surg. 21(3):188-195. PMid:18087935. http://dx.doi.org/10.1647/1082-6742(2007)21[188:R0 ACLA]2.0.CO;2.

MacCoy D.M. 1992. Treatment of fracture in avian species. Vet. Clin. N. Am. Small Anim. Pract. 22(1):225-238. http://dx.doi.org/10.1016/S01955616(92)50016-X.
Rutherford S. \& Ness M.G. 2012. Effect of contouring on bending structural stiffness and bending strength of the 3.5 titanium SOP implant. Vet. Surg. 41(8):983-987. PMid:23198925. http://dx.doi.org/10.1111/j.1532950X.2012.01055.x.

Teixeira C.R., Rahal S.C., Lima A.F.M., Correa M.A., Queiroz P. \& Vulcano L.C. 2004. Haste intramedular de polipropileno, combinada ou não a biomateriais, no tratamento de fraturas induzidas no úmero de pombos. Arch. Vet. Sci. 9(1):67-72. http://dx.doi.org/10.5380/avs.v9i1.4048. 